\title{
Research on Innovative Orientation of Art Design of News in the Era of Media Convergence
}

\author{
Kai Liu \\ School of Art and Design \\ Henan Institute of Engineering \\ Zhengzhou, China 451191
}

\begin{abstract}
With continuous development of information technology, the development of various media also becomes increasingly fast. The integration between traditional media and new media becomes an inevitable process. In media convergence era, the design of news fine art also has basis for innovation. This article analyzes and discusses innovation of art design of news under media convergence era, looking forward to improving level of art design of news.
\end{abstract}

Keywords-all media era; art design of news; innovative strategy

\section{INTRODUCTION}

With rapid development of information era, media industry also reforms accordingly, turning from traditional newspaper to new media, which has rich types, such as Self-Media, network media and electronic era. In the course of development of current society, traditional media still plays a very important role. Under all media age, the integration of all media becomes an inevitable development trend. Comprehensive application of all media provides certain conditions for innovation of art design of news, makes contents of news fine art media more novel and the forms richer, as well as offers a more perfect platform for presentation of news content. Under the era of media convergence, it is necessary to exert advantages of different media, apply them in the process of art design of news and embody originality of art design of news.

\section{PRINCIPLES OF ART DESIGN OF NEWS UNDER MEDIA CONVERGENCE ERA}

Under the background of information era, the transfer of a variety of news information shall realize rapid spread. A basic principle of fine art design is to ensure timeliness and conciseness. Timeliness is a principle produced for newspaper with special text. News with timeliness is valuable. Conciseness is also a problem that art design of news shall take into consideration. In order to make the picture of news more concise, it needs to do simplified treatment on visual elements in the picture of news and reserve visual elements related to theme and embody concision of news through various means such as fading and virtualization. Art editors should organize and process a great deal of information and make audiences rapidly accept information. For example, in the process of art design, classifying digital information and picture information can make audiences clear at a glance when reading news and understand contents of news more clearly.

\section{METHODS OF ART DESIGN OF NEWS UNDER MEDIA CONVERGENCE ERA}

\section{A. Update Traditional Idea of Art Design of News}

From the perspective of news transmission, art design is a means of propaganda. The art design of news is required to be concise, vivid and convenient for people to remember. In all kinds of art design of news, the design language that leaves deep impression on people can produce unexpected results. It is the charm of art design of news to attract people's attention through art design and make them have great interest in news contents. Reform of traditional media and application of new media causes earth-shaking changes for our life. Common forms of new media have network media, self-media and electronic media. New media is greatly different from traditional media and has certain uncertainty. Integrative development of traditional and new media makes idea in the field of art design in news industry change correspondingly. In the era of all media integration development, it has increasingly high requirements for art design of news. On transmission platform of new media, traditional graphic design will make news suffer an eclipse. In the course of continuous innovation and development of art design of news, people gradually realize the important role played by interestingness of language of art design of news in news propaganda and look forward to strengthen creative design of art design of news to make people deepen the interestingness and impression on news contents. In the course of future development, employees in news industry especially art editors shall strengthen the change for idea of art design of news and use new elements to make art design of news more interesting. Under the background of information era, people contact richer and richer foreign cultures, which have very important significance on expansion of thoughts. In the future, it is necessary to guide art editors of news to develop thoughts with the help of new media and let them enrich originality of art design of news through making use of foreign cultures. 


\section{B. Use New Media Resources to Strengthen Individual Design of Picture Elements in News}

Pictures in news are important element in art design of news and play the role of attracting people's attention. Generally speaking, video news is more attractive. In many times, art design of news still focuses on graphic design. In art design of news, pictures and text are indispensable important elements, but the effect of images is obviously stronger than text. Therefore, in the process of art design of news pages, in order to improve visual effect of pictures in news, we shall carry out individual treatment on pictures in news and show them directly or indirectly. The design of pictures in news shall conform to the gist of news. For example, if reporting entertainment news, we can design bigger pictures, which should have relationships with characters and words can be fewer; if reporting news in society such as the work of sanitation workers, we need to strengthen reasonable selection of pictures, which should conform to gist of news report and strengthen selection and application of news reflecting work of sanitation workers, to arouse people's cognition for hard work of them and show understanding and sympathy for them, and reduce their workload through behavior restriction. In the process of news art design, in order to improve visual effect of picture elements in news, we can reinforce application of all kinds of resources in new media platform. For example, for news reports with stronger theoretical property, we can intensify application of abstract pictures, which can transfer concepts and relatively novel thoughts and organically combine with news contents of stronger theoretical property. Therefore, in modern art design of news, abstract pictures become more and more and bring increasingly strong visual feelings for people. There are two kinds of abstract pictures in news. One is to use dot, line and plane to form geometrical morphology; the second is to use accidental patterns, such as paper wrinkle pattern, water paint pattern, ice crack pattern and watercolor rendering effect. News art design that uses abstract pictures often let people have simple or rational and tight sense of order and then produce strong visual impact.

\section{Highlight Timeliness of News}

Timeliness is a basic principle and life of news. Without timeliness, news cannot be called news and lose its value and meaning. The art design of news shall also meet the requirement for timeliness. Journalists shall edit and arrange organized news contents in shortest period of time. Meanwhile, art editors also need to design news into complete layout in the shortest time, form the best figurative expression and convey news contents to audiences in the first time. It leaves short time for art editors to edit news report, so it needs art editors to have skillful operating skills and finish art packaging of various news in the shortest time. In the process of art design of news, a lot of software is needed. After art design is finished on computer, it also needs the process of rendering. If we use software such as 3D MAX and MAYA in art design of news to build a relatively complex three-dimensional way, the process of rendering needs to cost more time, which is a problem remained to be solved in software of art design in the future. At present, in the field of television, the most frequently-used is VIZ technology. The operating principle of VIZ technology is similar to AE nonlinear software and can provide timely rendering service. It is a relatively mature editing technology for fine art of news, but it also has defects, so we need to strengthen development and application of new editing software of art.

\section{Strengthen Details Design of News}

In art design of news, the dispose of many details is important process to improve appeal of news, including text process and color processing. Firstly, for color processing, we should make key information of news striking. The color of fine arts is important element of news. The application of color can show subject content of news and make readers know it in the first time when reading news, grasp key information and realize rapid reading. So in design course of color, art editors can research and apply various colors. When choosing colors, they shall base on property and gist of news. For example, if the news is to mourn someone, they should use gray or black instead of bright colors. For some key information, they can process it through blackening and adding shading to highlight it. If the news taking scenery as the theme, they can choose rich colors to match up colors in scenery pictures and change the color of text to make the news more striking. Secondly, they need to pay attention to disposing text of news. The font selection of news can change according to different contents. Although in the same news, different contents can use different fonts. For example, they can edit main body with Song typeface and use other fonts such as regular script and imitation Song-Dynasty-style typeface for comments and contents for extended reading to highlight them for readers to distinguish and read.

\section{E. Strengthen Integration of Media Technology}

Traditional art design of news is graphic design in general. Although the graphic design at present is still a mainstream, with application of new media, various forms of art design of news also begin to appear. In art design of news, we can use network technology and information processing technology to combine resources such as text, audio and video to make news contents richer, and meet requirements of new media for news contents under all media environment. It changes news model with single combination of text and pictures in traditional news and make news contents have strong visual impression and lets people receive richer news contents when watching video news. When transferring news contents on different media platforms, we need to design the size and proportion of news. For example, when playing it on television, we need to adopt 4:3 standard definitions and keep headline and program parade of traditional news; when playing it on the internet, we need to base on big screen display to design resolution ratio of news. The resolution ratio is often above $1280 * 720$.

\section{CONCLUSION}

To sum up, in the course of art design of news, application of different media platform makes contents and art design forms of news become richer and richer. Under the background of all media era, it is necessary to change design idea of art editor and strengthen application of all kinds of new elements and new technology in the process of design, thereby improve the level of art design of news. 


\section{REFERENCES}

[1] Zhang Linfeng, Dong Qian. Breakout of TV Advertising under the Background of Media Convergence-Take Advertisement Management of Hunan Satellite TV as an Example [J], Media Time, 2011(09)

[2] Zhou Wei, Zhang Ying. Discussion on Innovation of Radio Management under the Background of Media Convergence [J], China Radio, 2011(05)

[3] Duan Chunlin, Yu Xiaochuan. Research on Influence of Involvement of Propagation Model on Brand Communication [J], Modern Communication (Journal of Communication University of China), 2010(11)

[4] Wang Huiling. Communication Strategy of Low Cost Brand under Perspective of Integrated Marketing Communication [J], Media Observer, 2010 (10)

[5] Zhou Chenghua, Wen Yuanzhu. Let Newspaper "Move"-Innovation of Page Layout of Newspaper in All Media Era [J], News Front, 2012(12) 